Provided for non-commercial research and education use. Not for reproduction, distribution or commercial use.

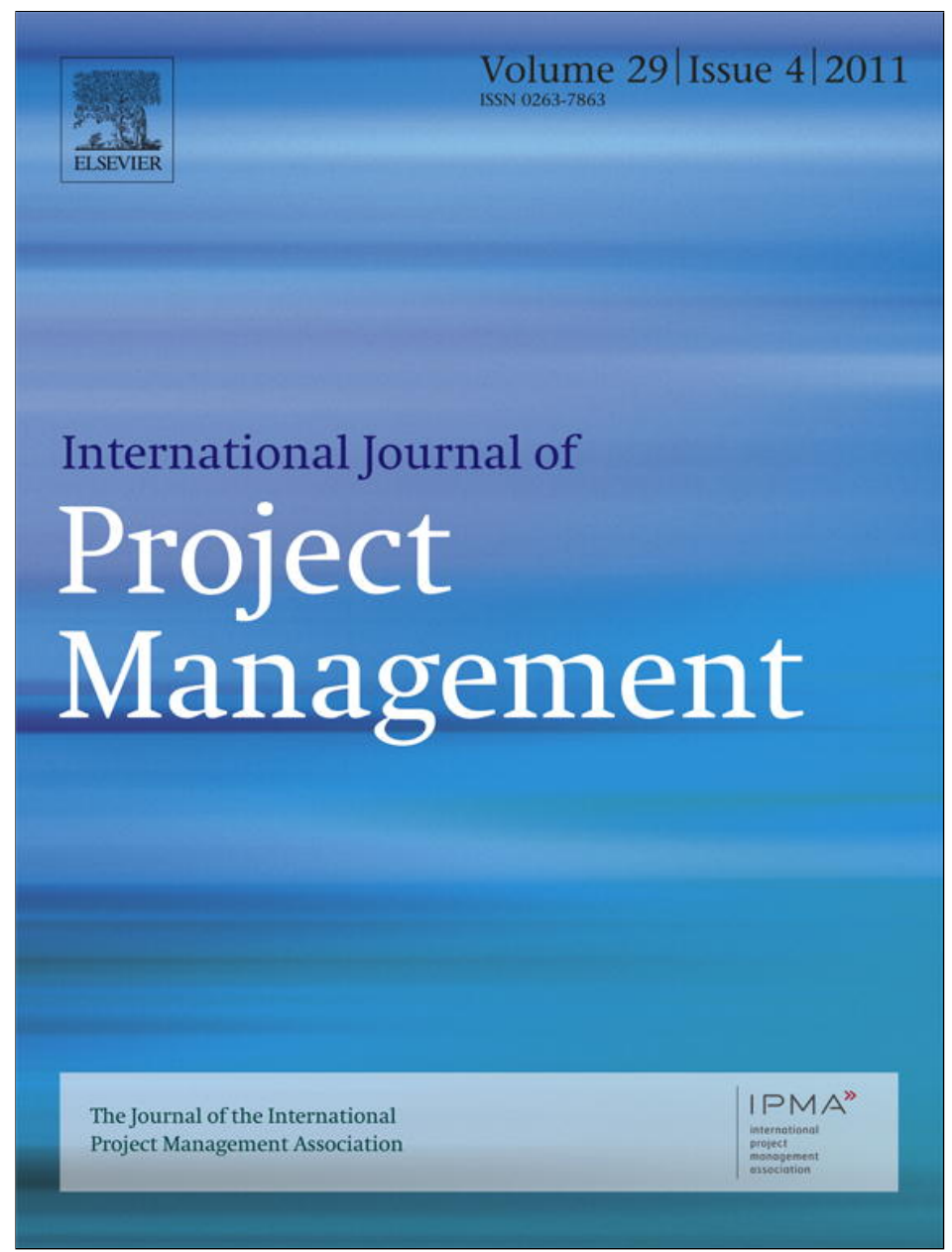

This article appeared in a journal published by Elsevier. The attached copy is furnished to the author for internal non-commercial research and education use, including for instruction at the authors institution and sharing with colleagues.

Other uses, including reproduction and distribution, or selling or licensing copies, or posting to personal, institutional or third party websites are prohibited.

In most cases authors are permitted to post their version of the article (e.g. in Word or Tex form) to their personal website or institutional repository. Authors requiring further information regarding Elsevier's archiving and manuscript policies are encouraged to visit:

http://www.elsevier.com/copyright 


\title{
Great expectations and hard times: The paradoxical experience of the engineer as project manager
}

\author{
Damian Hodgson $^{\mathrm{a}, *}$, Steve Paton ${ }^{\mathrm{b}}$, Svetlana Cicmil ${ }^{\mathrm{c}}$ \\ ${ }^{a}$ Manchester Business School, University of Manchester, United Kingdom \\ b Strathclyde Business School, University of Strathclyde, United Kingdom \\ ${ }^{\mathrm{c}}$ Bristol Business School, University of the West of England, United Kingdom
}

Received 17 August 2010; received in revised form 6 January 2011; accepted 11 January 2011

\begin{abstract}
While tensions between technical and management functions in organisations have long been recognised, very little research examines this relationship empirically in light of the emergence of project management as an (apparently) attractive career route for engineers and other technical specialists. This paper empirically explores these tensions, identifying various contradictions between the discursive legitimation of project management and the lived experience of project managers. Drawing on a series of structured group discussions with project managers from a range of industrial sectors with an engineering background, the paper illustrates the tensions implicit in the transition from technical specialist to project manager, and provides empirical evidence of the conflict between discourses which extol the importance and value of project management as an organisational imperative and the far more mundane experiences of project management as practiced in the real world, posing fundamental questions about the status and influence of project management in contemporary organisations.
\end{abstract}

(C) 2011 Elsevier Ltd. and IPMA. All rights reserved.

Keywords: Career; Engineers; Authority; Profession

\section{Introduction}

In recent years, projects have increasingly been promoted as "universally-applicable templates for the deliberate integration of diverse specialisms, enabling the organisation of flexible, autonomous, and knowledgeable individuals into temporary teams for the timely, efficient and effective accomplishment of defined goals" (Hodgson and Cicmil, 2007: 222), and therefore as an organisational form and management technique supremely suited to the new knowledge-based capitalist economy (Boltanski and Chiapello, 2005). Some have described this trend towards project work and project organisation as a process of 'projectification' (Lundin and Söderholm, 1995), and emergent work has pointed to the widespread failure to address the social and political consequences of 'projectification' for

\footnotetext{
* Corresponding author. Tel.: +44 161 3068791; fax: +44 1613063505

E-mail address: damian.hodgson@mbs.ac.uk (D. Hodgson).
}

both project managers and the project managed (Hodgson and Cicmil, 2006; Cicmil et al., 2009).

Increasingly, projects are depicted as the means to deliver new products, innovative organisations and even change itself in uncertain and knowledge-intensive business environments (Drucker, 1988; DeFillippi and Arthur, 1998; Whitley, 2006). At an organisational level, the consequences of this shift have typically been identified in the changing form of organisations, away from the traditional 'machine bureaucracy' towards matrix organisations in the 1970s (Davis and Lawrence, 1977) which remains the prime organisational structure to accommodate organisations which rely upon projects for the production of goods, services, or knowledge (Ford and Randolph, 1992; Hobday, 2000). Organisations operating in the fields of engineering and other technical domains are particularly likely to operate a projectified structure and therefore to rely, explicitly or implicitly, on a cadre of professional project managers, largely drawn from among the ranks of technical specialists, often on the assumption that a level of technical expertise is essential for the effective oversight of the technical aspects of the work process. 
The growth of project management has therefore been mirrored by the number of employees who are now choosing to take on project management roles (Kunda, 1992) and partly as a consequence, project management has developed into a discrete occupation - some would describe it as a new profession (Hodgson, 2007, 2002; Hodgson and Muzio, 2011) - with the emergence of dedicated training courses and rapidly expanding professional associations - the US-based Project Management Institute (PMI) now boasting some half a million members and credential holders in 185 countries (PMI, 2010). As a result, project management is gaining a significant influence in contemporary organisations, and is widely promoted as a parallel or indeed more attractive career ladder for many technical specialists. The consequence of this process is a greatly altered occupational landscape for technical specialists engaged in career moves into managerial positions; arguably, one in which project management is a more attractive career option than ever before. Suggestions that the promises of a project management career prove to be far less satisfying in practice (Cicmil et al., 2009; Asquin et al., 2010) therefore merit more careful investigation and reflection.

This paper is intended as a first step in revisiting and reexamining this debate in light of the current status and trajectory of the project management discipline. In this paper, we identify and illuminate a number of tensions affecting the position and conduct of project managers by drawing on a specific set of reflective accounts from individuals who have moved from technical or scientific specialist roles to a position as project manager in a range of organisations. In particular, the paper provides empirical evidence of a conflict between corporate discourses which extol the importance and value of project management as an imperative for many organisations, and the far more mundane experiences of project management as practiced in the real world. The empirical research is drawn from a qualitative study intended to establish the main challenges facing technical specialists in project management positions, and forms part of a broader ongoing study into professionalisation, identity formation, and the changing profile and influence of the project management discipline. The study therefore addresses three key research questions:

1. How is project management as a career move perceived among technical specialists and what expectations do individuals have with respect to the work, authority and status associated with the $\mathrm{PM}$ role?

2. What is the nature of 'forces' that drive such a role change?

3. How do these project managers' experiences of their new role compare with these expectations?

\subsection{Technical specialists and managers: a history}

The tension between the technical specialist and technical manager roles is not a new theme in management or in research, and discussions on the work values of engineers and engineering managers exist since the 1960s. However, although the earliest research in this area predates the existence of professional associations for project managers, with a handful of exceptions (e.g. Allen and Katz, 1995; El-Sabaa, 2001; Hölzle, 2010), even the most recent work makes little reference to the rapid growth of project management since the 1990s, nor associated developments such as the growing professionalism in the field, indicated by the establishment of a proprietary body of knowledge for the discipline and increased shift towards credentialism in project management labour markets (Morris et al., 2006). There is a long history of research examining the relationship between engineering and management functions in organisations. Much of this work, following the lead of Kornhauser's (1962) influential Scientists in Industry $^{1}$, is concerned with establishing the location, affiliation and culture of engineering in the workplace and modern corporation, the level of interest in this theme in the second half of the 20th century reflecting the economic and political importance of engineering and production in the postwar and Cold War context. For Kornhauser (1962) and others (e.g. Raelin, 1986), there exists a fundamental tension between the work values of scientists and engineers and the priorities of the organisations, public and private, for whom they work; in terms of the goals of each group, the control system preferred/expected, the incentives put in place and the source of legitimacy drawn upon. Kornhauser's work, although seminal, mirrors to a large extent the standard professionalism literature of the time, identifying engineers unequivocally as professionals, idealising the exceptional character of professionals and thereby stressing the conflicts between professional and corporate value systems.

The tenor of subsequent work in the 1960s and 1970s was broadly unconvinced by this thesis, and a consensus formed that in various respects, engineers are in fact much closer to management than comparable technical occupations such as research scientists; in terms of their social background, work values, orientation towards career (Perrucci, 1971; Kerr et al., 1977). This research tended to question the strength of professional culture in engineering, arguing in particular that engineers are largely more 'local' than 'cosmopolitan' in orientation (Shepard, 1956), in that, unlike traditional professionals, they typically recognise the right of non-engineers within their organisation to supervise and assess their work, have a greater commitment to their employer than to their field of specialism, and they tend to focus on organisational rather than generic questions, problems and challenges (Ritti, 1968). Hence Zussman (1984; 221) argues in his study of engineers in the US, that "with some qualification, they identify and sympathise with Management".

More importantly, various researchers argued that, in marked contrast to traditional professionals, a large proportion of itinerant engineers aspired to a management role; according to Perrucci (1971), some $40 \%$ of new engineers had the intention to eventually take on a management role. This expectation is captured by Everett Hughes' acerbic comment "the engineer who, at forty, can still use a slide rule or logarithmic table, and make a true drawing, is a failure" (Hughes, 1963, p. 137). The import of much of this work is clear - those engineers who, in mid- to late-

\footnotetext{
${ }^{1}$ There is also of course a century-long debate over the influence of scientific management and related aspects of engineering rationality on production management and organisation theory; the literature relating to this movement and its impact is extensive but is not germane to the discussion below; for a useful summary, see Shenhav, 1999).
} 
career, have not moved into management roles, are considered 'failures' and ensuring their continued motivation is seen to be a challenge for many organisations. For those who choose to remain in the technical specialism, "identification as a professional (engineer) has become a way to redefine failure as success" (Goldner and Ritti, 1967, 490, quoted in Perrucci, 1971: 490).

Several authors argue that engineers' openness to managerial values and goals, and their managerial career aspirations, are a reflection of the pragmatism and instrumentalism inherent in engineering as a discipline; thus it is claimed that;

"Engineers are not on the whole concerned with knowledge for its own sake or even with autonomy, independence and selfregulation. An engineer's most important peers are those who judge his work in the immediate context with regard to effectiveness and cost. Technical success (a goal of engineers) is reasonably consonant with the commercial and other goals of most employing organisations" (Glover and Kelly, 1987: 204).

Watson and Meiksins (1991: 142) suggest, in a similar vein, that "committed to technical ideals, (engineers) are trained for applied work and are therefore predisposed to accept a certain amount of compromise with organisational requirements". Thus, for many engineers, what Causer and Jones (1996: 108) call "an anticipatory identification with management values and objectives" is natural and unsurprising given the presumed trajectory of their career. Other contemporary writers maintain that the organisation plays a major role in persuading engineers to take on management roles; either deliberately, through the creation of dual career ladders and systems of incentives, or by omission, by failing to provide sufficient rewards, promotion opportunities or expected levels of autonomy for career engineers (Rynes et al., 1988). For some, then, the move from engineering to management involves a diversion and distraction from a strong technical vocation, reinforced by extended training and induction into their particular engineering culture;

"It is also worth noting that even where their work is now largely removed from day-to-day technical activities, technical managers typically came into engineering because of a technical enthusiasm. Being a technical person, being an engineer, has often been central to their self-identity (...) Some at least will have found themselves entering management more by accident than design, and even where entry to management has been a longstanding goal this does not necessarily reflect a declining interest in technical issues" (Causer and Jones, 1996: 117).

This raises the prospect of engineers being forced unwillingly into management roles against their technical and professional orientation, making reluctant and ineffective managers (Roberts and Biddle, 1994). Hence it is argued that;

"Many authors regard the truncated technical career path faced by many engineers to be the primary reason why they consider a transition into management. If engineers wish to achieve higher salaries, they may be faced with little choice but to consider the move" (Johnson and Sargeant, 1998: 43-44).
A full understanding of the relationship between engineering and management, and the impact of the growing occupation of project management, thus requires an analysis of both those factors driving and also those impeding engineers from undergoing the career transition from engineering to management positions.

\subsection{The price of transition from technical specialist to manager}

Much of this work presents the move from engineering to management as a difficult and dangerous choice (Roberts and Biddle, 1994; Johnson and Sargeant, 1998; Yeh, 2008), emphasising both the likely costs and benefits the technical worker would encounter in a transition to a managerial role, and presenting a familiar dilemma to mid-career specialists;

"If [the professional] chooses to remain within his technical specialty, he will usually be required to forego the increased pay, power, status symbols and other amenities associated with higher office. Furthermore, he will be continually subjected to such constraining uncertainty-reduction devices as job descriptions, rules, and standard operating procedures... On the other hand, should the professional seek promotion to higher organisational levels, he will increasingly be called upon to perform tasks which are administrative or managerial. Thus he must choose between remaining in his technical specialty and tolerating numerous interferences with his autonomy, or relinquishing precisely those tasks which permit him to employ his professional and technical skills" (Schriesheim, Von Glinow \& Kerr, quoted in Kerr et al., 1977; 336).

A stream of more recent work looks at how to incorporate professionals and expert occupations such as engineers into bureaucratic organisations (e.g. Raelin, 1986; Mignonac and Herrbach, 2003), using for example dual career ladders (Allen and Katz, 1986); through the creation of professional-administrator role, or the use of a matrix organisation. Dual career ladders appear particularly as popular techniques to solve this difficulty, although numerous problems have been identified with this particular solution (Shenhav, 1988; Johnson and Sargeant, 1998). The fundamental weakness of this approach is that;

"technical employees may not believe in the company line of "separate but equal." There is a widespread perception among scientists and engineers that parallel, dual-career ladders are a myth and that, in fact, upward mobility and influence in the organization, with their associated rewards, only come by moving into management ranks." (GomezMejia et al., 1990: 71).

Contrary to the assumption by many researchers that engineers assume management roles due to a lack of interest or ability in the technical elements of their occupation, research by Biddle and Roberts (1994) indicates that technical and managerial ability is frequently correlated in engineers, and that "engineers aspiring to enter management are often among the more proficient technically" (Causer and Jones, 1996: 117). "This adds some fuel to the argument that competent and successful engineers are 
effectively 'lost', with some cost to the organisation, as they shift instead to managerial roles" (Gomez-Mejia et al., 1990). Elsewhere, however (Roberts and Biddle, 1994), they maintain that this danger can be averted by HR interventions to train and motivate both engineer-managers and career engineering specialists.

Furthermore, it is widely argued that this technical proficiency is central to their effectiveness in management positions, not least because management of technical staff and technical processes requires an understanding of the complex detail of activities, based on the common premise that "a certain minimal amount of technical ability is required to manage the work of technical employees, making it wise to hire managers and supervisors from among technically trained professionals" (Roberts and Biddle, 1994: 563). This argument is taken further by Johnson and Sargeant (1998) who maintain;

"Lam (1996: 207) concludes that 'an increase in the number of engineers in management positions on its own is of no use if those promoted to management have to abandon their technical identity and cease to regard engineering expertise as relevant'. It is therefore possible to argue that organisations should not view the transition into management of a technical employee as a cost in terms of lost expertise" (Johnson and Sargeant, 1998: 44).

This position is developed in recent work which argues that the technical/managerial distinction is overplayed in much of the literature (Shenhav, 1988), and that the shift toward projectbased work organisations has resulted in a range of "hybrid organisational positions which both formally and informally combine elements of managerial/supervisory and 'expert' or 'professional' work" (Causer and Jones, 1996: 119; see also Bailyn, 1991).

In the remaining sections of the paper, then, we examine reflective accounts of practicing project managers as expressed in structured discussions with other project managers to examine the current experiences of project managers with technical specialist backgrounds, directed by the three research questions set out above. We use these accounts to discuss the ways in which the project managers reflect on their self-created or allocated position and responsibilities within projectified environments. In particular, the accounts draw a marked contrast between the corporate discourse on the value and centrality of PM in modern industry and the lived experience of many project managers. The empirical material focuses attention on the consequences of the constitution of the project manager as an attractive yet insecure occupational role in many modern organisations.

\section{Methodology}

The empirical research was conducted through a series of structured group discussions, a method chosen for both methodological and pragmatic reasons. In a pragmatic sense, the group discussion enabled the acquisition of rich data while allowing for the flexible exploration of research themes in a cost-effective and time-effective manner (Frey and Fontana, 1991; Gibbs, 1997). Methodologically, the value of the group discussion was the opportunity to observe the construction of a work identity in a social setting, allowing for the "synergy, snowballing, stimulation, and spontaneity" that a group dynamic can generate (Catterall and Maclaran, 1997: 1.3). Given our broadly phenomenological and interactionist perspective, the group discussion was valuable in that it allowed us to examine the interplay and intersubjective modification of opinion through the course of the encounter, a dimension which makes this form in many ways 'more ecologically valid than methods that assess individuals' opinions in relatively asocial settings' (Morgan, 1993: 54).

The research involved five groups which were convened in south-west England and central Scotland between December 2004 and April 2007 (see Table 1). All of the research participants were project managers or had project management responsibilities, all but two were male, and all were located in organisations with a structure which was to a greater or lesser extent 'project-based' (Table 1). All five focus groups included participants with different levels of experience and from distinct occupational backgrounds, but who shared a technical specialisation prior to taking on a project management role. Participants were recruited through a non-purposive, snowball sampling technique, drawing on personal contacts of the authors across a range of organisations within technical or engineering-oriented industries.

The group discussions were semi-structured, following a core set of themes; work history, professional identity, PM professional affiliations and PM knowledge employed. Participants were informed of these themes at the outset, after which discussion was initiated and maintained by two facilitators in each group. The discussions were recorded, transcribed and then coded with the aid of Atlas-ti qualitative data analysis software according to themes derived from relevant literature and/or developed inductively from the empirical material itself. At the same time, to avoid fragmenting the data by this coding process, the transcripts were read through and considered holistically, to reveal recurrent themes and emergent positions/ tensions through the course of each encounter.

Table 1

Focus group participation, by sector and region.

\begin{tabular}{llll}
\hline Focus group & Region & Number of participants & Composition of focus group by sector (identifier code in brackets) \\
\hline 1 & SW England & 3 & Local Govt (LG), Defence (D1/D2) \\
2 & SW England & 5 & Construction (C1), Aero (A1), Defence (D3/D4/D5) \\
3 & SW England & 3 & Defence (D6), Construction (C2), IT (I1) \\
4 & Central Scotland & 3 & Scientific Research (S1, S2, S3) \\
5 & Central Scotland & 2 & IT (I2, I3) \\
\hline
\end{tabular}




\section{Analysis}

In this section, we discuss the ways in which the focus group participants reflected on their own views of the role of the project manager and specifically their experiences of the tension between the rhetoric of the importance of project management as an organisational imperative and the more mundane perceptions of it in the real world in which it is practiced. We will discuss these two aspects of the discussion in turn.

\subsection{Project management as vital and ubiquitous}

First there is strong evidence from this empirical data to indicate that it was a widely-held view that project management is increasingly recognised as important as a means to structure and manage work, and that the recognition of project management as a discipline is increasing;

"You are hearing the terminology project manager used more often and people are beginning to recognise what it is and understand it as a profession in its own right." [S1]

This growing 'awareness' for some encompassed a belief in project management as the means to reduce complexity and chaos in terms of managing responsibilities in modern organisations; hence PM is seen as;

“giv(ing) you a far better idea on what you've got to do, when you've got to do it and some of the difficulties and issues you need to use." [D3]

Moreover, strong claims were articulated that the greater use of project-based approaches and techniques would enable organisations to bring back a discipline that has become eroded due to the introduction of more flexible and chaotic work systems.

"I think we are actually going to be able to bring our projects into time, cost and performance, I think we will see that. I would realistically say give us another 5 years and hopefully you won't be seeing those really bad reports in the paper that you are seeing at the moment!" [D1]

Moreover it was proposed that rather than an 'organisational bolt-on', project management is increasingly recognised as;

"the fundamental thing that will make us as an organisation work." [D1]

In addition to the belief that project management is a necessary tool to be used in management practice the following quote is typical of a slightly different narrative that was present throughout the course of the research. This narrative is complementary to the view that project management is critical to organisational success but exemplifies the more fundamental view that the practice of project management is not something that is new that needs to be introduced to the organisation but is already inherent in all organisational work.

"I've thought about it over the years, everything is a project, no matter what you're doing. As I think back even to an engineer, just simple little things you do there was a project behind it. But then you went into various other things, like you're into industrial relations, there was a project in there as well, it was maybe to introduce some productivity system. You had to apply all the same principles, but it was more softoriented, rather than hard-oriented, you had to manage the relationship." [I2]

This view is expanded upon by this participant who believes that the practices that comprise project management have always taken place but often under other names therefore the emergence of project management is really an emergence of a new terminology. This suggests that what is happening in contemporary organisations is little more than a re-labelling of previously used methods.

"...I mean, project management has always been there, there's people been doing it, it's not been called project management, but projects have happened, have been delivered and our operations manager has been involved in loads of those and managed most of those. But some of the formal techniques that are coming through now are relatively new and he wouldn't be aware of them and I suspect a lot of other people wouldn't be aware of them." [S1]

This view is echoed with more certainty here where this participant is sure that with the change of job title came very little change in the content of the work between the engineering role and the project management role.

"My job title is project manager; I've been doing project management formally for the last approximately five years since we started a project management group in $\mathrm{ABC}$. Prior to that, I believe that I did do project management, but it probably wasn't recognised as such at the time." [S2]

There was evidence of this similarity at a more detail activity level as the similarities in activity between the role of the project manager and the aircraft navigator are highlighted.

"a major part of that was a flying career as a navigator, planning every trip, which in essence is a very specific type of project, lots of planning and certainly risks involved. You don't deal with it as a project, you deal with it as a trip, but a lot of the similarities are there." [I1]

In addition to individual tasks, project management methodologies were also recognised at the departmental level indicating that even when project management is not practiced as a whole some of its parts are recognised in isolation much like the emergence of letters of a word before the word itself is understood.

“It's interesting, the way we've developed our thinking over the last few months is that everyone needs project... mainly in our department, these project management skills. I use that quite specifically, rather than being a project manager, everyone needs project management skills because project management is about taking forward change of any description." [D3] 
At organisational level this influence of project-based methodologies was also recognised. The following quote describes an organisation's attempt to align itself to the methodology promoted by the Association of Project Mangers and its finding that, in fact, little in terms of process and practice needed to be changed.

“...but it's quite interesting, earlier on when we aligned ourselves to the APM, there were only two elements that we had to add to meet our business, and those were specific to us, the rest of it meets what we do." [D1]

The ubiquity and importance of project management practice is summarised concisely here.

"I've thought about it over the years - everything is a project, no matter what you're doing." [I2]

In a more extreme way the following participant clearly places project management at the centre of everything that is done in the organisation, while recognising her own deeply-held assumption that project management is a technical role.

"I've spent 19 years in the MoD and I still think in my own mind a project manager being a techie person. But I am preaching to everybody that everybody is a project manager (...) But hey (laughs), what can you say?” [D1]

Collectively, these statements reflect a belief in the growing recognition of project management, a conviction of the broad applicability of project management across the organisations and a faith in the capacity of project management methodologies and approaches to transform operations within organisations. Alongside this, more interestingly, is a process of revisionism, of reinterpreting previous activities as project management avant la lettre, or perhaps more dangerously, of project management being little more than the formalisation of existing practice in engineering management.

\subsection{Project management as mundane and lacking status}

Contradicting many of these assertions of the importance placed on project management practice, however, the empirical data also contains some 370 direct references which collectively reveal the more conflicted experience of enacting the role of a project manager in specific organisational settings. While a conviction in the importance and centrality of project work was shared by most participants, many were then discouraged by the failure of their organisations to embrace this discourse. Indeed, even in sectors where project working was well-established, such as construction and defence, most project managers experienced ambivalence or a more explicit rejection of the value and status of project management. This was evident even at the most basic level of perceived usefulness of training and qualification in the area of practice.

"People were coming to me and saying 'why are you doing this, it's a numpty qualification? It doesn't mean anything, it was so easy to do. What benefit to us as an organisation is it?"' [D1]
As a result, a certain discomfort with the title of project manager was quite common, typically linked to concerns over ignorance or lack of respect by peers in other fields, or in the project managers' previous (and often more established) disciplinary area, such as engineering, quantity surveying, etc.

"Certainly with people I was dealing with outside, I would say I manage projects, because it starts to explain what I do, but that results in a blank look, at which point you have to explain further!" [D5]

To counter such challenges, several research participants engaged in quite complex identity politics, strategically deploying other (more established) identity claims, reverting to their previous occupational title; changing the title of project manager to another (such a 'consultant'); or rephrasing the term project manager to one with a more credible association such as project engineer. Those without a strong prior professional affiliation seemed to be more ready to adopt the title project manager while others, with stronger professional affiliations, tended to retain or adapt their previous professional affiliation.

"I always call myself a civil servant... because I am." [D3]

"I use the word consultant and when it says sector, construction industry is what I do, so that sums it up." [C1]

Tellingly, none of the established project managers suggested that their position provided greater autonomy in reality, in terms of decision-making and discretion. On the contrary, the accounts tended to suggest that project management was more often experienced as a new form of bureaucracy due to its emphasis on plans, processes and formalised procedures. Hence, where transition to the project manager role implied increased status and seniority, a common experience was that the decision-making authority that should accompany this position was taken away and given to a subject expert such as a chief engineer or functional manager.

"Invariably I think that decision anyway is taken from somebody at the next level, you know, you've got the construction manager above." [C2]

The gap between the level of accountability carried by the project manager and her/his status, resources and influence were underlined by several participants.

“A project manager will take the blame if it fails, don't get me wrong, but you know, in terms of driving the success of that programme, the options are limited because there are so many other people who are having so many other conversations that ultimately your job is... or sometimes, it's reduced to merely recording the sins of others." [I3]

Often this lack of autonomy and power was seen to stem from a lack of recognition for project management among senior management.

"Project manager was really a title, it was a job title, no more than that. I think I had no idea of project manager as a 
profession, really and I think my employers had no idea of project manager as a profession." [LG]

Surprisingly, and in spite of the lack of support, resources or autonomy afforded to the project manager, many attested with pride to the experience of intensive accountability and even strong feelings of personal ownership.

"Very often (...) you get embroiled in the sort of small stuff, (...) because there's nobody else to do it and the problem with being project manager is a lot of the time you don't have the resources so you are diving in to save things because it's very personal, it becomes your project, you want to see it happen." [LG]

The tensions examined here are illustrative of the gap between the construction of the practice of project management as attractive, important and influential, and the rather more challenging and frustrating experiences of those embracing this role. The empirical evidence illustrates both sides of this coin; the ubiquity, promise and increasing status of project management, immediately undermined by the intensified accountability, limited influence, lack of support and uncertain status of the new position.

\section{Discussion}

As noted earlier, with notable exceptions in the project management field (e.g. Allen and Katz, 1995; El-Sabaa, 2001; Hölzle, 2010), research into the relationship between technical specialisms and the management function rarely if ever reflects on the changing nature of the discipline of project management. This is particularly surprising as the managerial career path for many technical specialists is not directly to general management but typically to a project management position. One might expect that there would be some impact of the changing status of project management, supported by the significant efforts towards the professionalisation of the project management field, the establishment and rapid expansion of professional associations, and the standardisation of practice based on proprietary bodies of knowledge and associated accredited training for project managers (Morris, 1997; Morris et al., 2006; Hodgson, 2007; Hodgson and Muzio, 2011). To the extent that project management is recognised as a distinct and valued discipline in contemporary organisations, and makes more convincing claims for a kind of professional status, one would assume that this would ease the transition for technical specialists, making the project manager role more attractive and making it relatively easier to relinquish alternative identities as professional engineer or technical experts. The rising profile of project management may therefore be expected to encourage more technical specialists to make the move into project management, and subsequently, to be more content with this decision than would previously have been the case. Seen from the perspective of those choosing the career path towards a technical specialist rather than a managerial role, an enhanced status for project management might also undermine claims that there can be 'separate but equal' career ladders (Allen and Katz, 1986; Hölzle, 2010).
Our empirical evidence points instead to significant tensions in the experiences of the project managers participating in the research. On the one hand, the discursive promotion of project management has created, to some extent, the organisational and social contexts within which technical specialists in various sectors see the project manager role as one which promises status, influence and authority within particular organisational settings. The accounts of self-reinvention described above as engineers and other specialists join the 'accidental profession' of project management seem to be linked to a significant change in the last 10 years or so, reflecting a widespread recognition of the pervasiveness of PM (and project labelled activities) across sectors and the formalisation of PM in procedures and in job titles and career structures. In parallel, the PM role has gradually infiltrated into management structures in the same way that the tools and methods have filtered into management practice. PM is now becoming an opportunity for all ambitious people, especially lower level 'technical' employees with limited previous career options. The question of whether moving from a technical specialist role to a project management role is a ' $\mathrm{good}$ career move' appears, from the outside, to be shifting decisively in favour of project management. Becoming a project manager, and renouncing strong claims to technical expertise and professional status as an engineer, becomes relatively more attractive. On the face of it, PM tools and techniques are seen to apply across industries, and mastery of project management is perceived to be a vital organisational capability. This would suggest that, more than could have been imagined by the likes of Hughes (1963) or Perrucci (1971), PM increasingly becomes the natural and inevitable career choice for an engineer or technical specialist with any serious ambition.

On the other hand, while still maintaining this understanding of PM as vital and of their position in the organisation as equally vital, the same project managers describe their experiences of this role rather differently. The post-transition experience in the actual 'day to day' life of a PM is almost the opposite of the hype. The activity is often at a lower level than was anticipated, frequently including responsibilities of a 'glorified secretary' such as managing templates and schedules for delivery, and chasing up overdue tasks. In carrying out this more limited role, the expected (and perhaps necessary) authority, independence or control over budget is not given, leaving the project manager reliant upon negotiation skills to cajole cooperation, rather than any significant power. As a consequence, a consistent picture is given of an asymmetric balance between accountability and authority, where project managers are held accountable in many contexts for situations they perceive to be beyond their control. What status and perceived competence the project manager lays claim to is often disputed by project team members with competing technical or professional jurisdictions, such that the influence of project managers is diluted and undermined and their decision-making authority often curtailed by bureaucratic reporting structures.

Accompanying this is often a sensation of loss of professional status as new project managers relinquish their position as technical specialist, and renegotiating relationships with former colleagues. These tensions arise during the process 
of becoming a project manager as converts embrace a value system which affirms the importance and centrality of project management. We would suggest that claims made by our project managers for the value and potential impact of the discipline forms part of the discursive processes of identity formation, as project managers attempt to overcome historical imbalances of power across occupational boundaries. As the earlier literature on engineers and managers indicates the process of leaving behind an established and valued occupational identity is typically challenging - while the transition is often driven by the need to progress one's career, enhance one's status and expand one's role by making a step toward management, the accounts given suggest difficulties in making this transformation. These difficulties centre on the difficulty encountered in leaving what is often an established and respected occupation to enter what remains a newer, less recognised and often less valued occupation. These difficulties are increased where incumbents to project management positions lack the confidence and legitimacy provided by an established and externally-recognised training programme that familiarises the entrant with what is expected of them and the skills/competencies they require. These tensions do not abate as new project managers attempt to enact this role within an organisational context. Here, the conflict centres around the lack of institutionalised identity associated with the role, as the organisational identity of a project manager varies from an administrator/information gatherer to a senior manager accountable for the completion of major deliverables. Typically, both roles exist in the same organisation, or relate to the same position, such that the level of accountability is not matched by the resources or the authority to discharge the role. This situation is aggravated by the still fragile credibility of the occupation overall and a broader lack of understanding of the occupation, its capacities and its limits. One should recognise that the professionalisation of project management is very much a work in progress, and far from universally recognised, particularly in organisations built on the primacy of engineering or a similar technical/professional cadre. The levels of scepticism encountered by project managers across sectors undermine the confidence of those who assume the status of 'project manager', exacerbated and reinforced by the lack of authority and legitimacy of the role.

\section{Conclusion}

Our research findings provide some evidence for the existence of a gap between expectations and reality for technical specialists who take on project management roles, a gap which can be partly explained in light of a fundamental tension between the technical and managerial functions. Arguments of a 'fundamental tension' between the two functions may indeed be overstated, underestimating the similarities between engineering and managerial value systems; however, the rise in apparent prestige of project management, its value, influence and professional status, implicitly casts a shadow over alternative career paths, particularly in engineering and other technical professions. The enthusiastic embrace of project management as a ubiquitous and essential role in organisations by our research participants reflects a necessary shift as individuals relinquish their claim to technical professional status and rationalise their move into (project) management roles. The disillusionment, and the gap between expectations and reality, however, indicate that the tension continues to influence the decision to move and experiences post-transition, reflecting countervailing forces both driving and opposing career moves into project management.

The persistence of this tension requires further exploration and explanation. It appears that there are two often opposing forces at work which serve to create the tensions. First, the organisational need to embrace what are perceived as more flexible and high-performing organisational types that are created when project-based structures and methodologies are utilised and the accompanying rise in managerial roles required to facilitate and control work in such project-centred organisations. Secondly, despite the increasing attractiveness of this career route and the rhetoric at the organisational level of its importance, it appears that in practice, the project manager's role is typically compromised by structural and cultural aspects of the organisational and industrial contexts, the still-fragile credibility of project management and the lack of authority, resourcing and autonomy afforded to those taking up this role.

In this preliminary, scoping study, we have focused on common themes emerging across sectors and organisations, as evidenced in the focus groups. An alternative methodology, such as semi-structured interviews across a representative sample of organisations, would enable more nuanced exploration of the dynamics which constrain or enable changing authority, status and autonomy to the project management role. A more explicitly longitudinal study would allow the measurement of the pace of change, as one might predict that increasingly organisations may avail themselves of the growing number of project managers with professional credentials and higher-level qualifications in the discipline. An understanding of how this picture varies by country, by industrial sector, and also between and within organisations, represents a pressing question for project management as a field, and indeed for all organisations in project-based industries relying on specialist technical knowledge.

Our research findings so far introduce two key streams for future studies. Firstly, a broader, comparative enquiry could generate further understanding of the contextual factors in specific organisational environments that promote or reinforce the perception of project management as a valuable career step. Secondly, the themes explored in our pilot study can be revised in light of these findings to generate deeper reflection on the sources of tensions experienced by the project management practitioners, related to issues of identity formation, professionalisation and broader identity politics within organisations. Specific themes for further study should therefore encompass identity work, organisational and institutional changes, professionalisation and inter-professional competitions, autonomy, status, and authority of the transformed technical specialist. An understanding of how discrepancies between expectations and experiences are challenged, 
lived with or even rationalised by project managers is a vital first step to addressing this concern and building a realistic career structure and support system for the next generation of project managers.

\section{References}

Allen, T.J., Katz, R., 1986. The dual ladder: motivational solution or managerial delusion? R\&D Management 16 (2), 185-197.

Allen, T.J., Katz, R., 1995. The project oriented engineer: a dilemma for human resource management. R\&D Management 25 (2), 129-140.

Asquin, A., Garel, G., Picq, T., 2010. When project-based management causes distress at work. International Journal of Project Management 28 (2), 166-172.

Bailyn, L., 1991. The hybrid career: an exploratory study of career routes in R\&D. Journal of Engineering and Technology Management 8, 1-14.

Biddle, J., Roberts, K., 1994. Private sector scientists and engineers and the transition to management. The Journal of Human Resources 291, 82-107.

Boltanski, L., Chiapello, E., 2005. The New Spirit of Capitalism. Verso, London.

Catterall, M., Maclaran, P., 1997. Focus Group Data and Qualitative Analysis Programs: Coding the Moving Picture as well as the Snapshots. Sociological Research Online http://www.socresonline.org.uk/2/1/6.html accessed 6 December 2010.

Causer, G., Jones, C., 1996. Management and the control of technical labour. Work Employment and Society 10 (1), 105-123.

Cicmil, S., Hodgson, D.E., Lindgren, M., Packendorff, J. 2009. Project Management Behind the Façade. ephemera: theory \& politics in organization 9 2: 78-92.

Davis, S.M., Lawrence, P.R., 1977. Matrix. Addison-Wesley, Reading, Mass.

DeFillippi, R.J., Arthur, M.B., 1998. Paradox in project-based enterprise: the case of film making. California Management Review 40 (2), 125-139.

Drucker, P.F., 1988. The coming of the new organization. Harvard Business Review 66 (1), 45-53.

El-Sabaa, S., 2001. The skills and career path of an effective project manager. International Journal of Project Management 19, 1-7.

Ford, R.C., Randolph, W.A., 1992. Cross-functional structures: a review and integration of matrix organization and project management. Journal of Management 18 (2), 267-294.

Frey, J.H., Fontana, A., 1991. The group interview in social research. The Social Science Journal 28 (2), 175-187.

Gibbs, A., 1997. Focus Groups. Social Research Update 19 http://sru.soc.surrey.ac. uk/SRU19.html accessed 10 December 2010

Glover, I., Kelly, M., 1987. Engineers in Britain. Allen \& Unwin, London.

Gomez-Mejia, L.R., Balkin, D.B., Milkovich, G.T., 1990. Rethinking rewards for technical employees. Organizational Dynamics 18 (4), 62-75.

Hobday, M., 2000. The project-based organisation: an ideal form for managing complex products and systems? Research Policy 29 (7-8), 871-893.

Hodgson, D.E., 2002. Disciplining the professional: the case of project management. Journal of Management Studies 39 (6), 803-821.

Hodgson, D.E., 2007. The new professionals: professionalisation and the struggle for occupational control in the field of project management. In: Muzio, D. Ackroyd, S., Chanlat, J.F. (Eds.), Redirections in the Study of Expert Labour: Medicine, Law and Management Consultancy. Palgrave, Basingstoke.

Hodgson, D.E., Cicmil, S. (Eds.), 2006. Making Projects Critical. Palgrave, London.

Hodgson, D.E., Cicmil, S., 2007. The politics of standards in modern management: making 'the project' a reality. Journal of Management Studies 44 (3), 431-450.

Hodgson, D.E., Muzio, D., 2011. Prospects for professionalism in project management. In: Morris, P.W.G., Pinto, J., Söderlund, J. (Eds.), The Oxford Handbook of Project Management. Oxford University Press, Oxford.
Hölzle, K., 2010. Designing and implementing a career path for project managers. International Journal of Project Management 28 (8), 779-786.

Hughes, E.C., 1963. Professions. Daedalus 92, 655-688.

Johnson, D., Sargeant, A., 1998. Motives for transition: an exploratory study of engineering managers. Human Resource Management Journal 8 (3), 41.

Kerr, S., Von Glinow, M.A., Schriesheim, C., 1977. Issues in the study of professionals in organizations: the case of scientists and engineers. Organizational Behavior and Human Performance 18, 329-345.

Kornhauser, W., 1962. Scientists in Industry: Conflict and Accommodation. University of California Press, Berkeley.

Kunda, G., 1992. Engineering Culture. Temple University Press, Philadelphia, PA

Lam, A., 1996. Engineers, management and work organisation: a comparative analysis of engineer 's work roles in British and Japanese electronics firms. Journal of Management Studies 33 (2), 183-212.

Lundin, R.A., Söderholm, A., 1995. A theory of the temporary organization. Scandinavian Journal of Management 11 (4), 437-455.

Mignonac, K., Herrbach, O., 2003. Managing individual career aspirations and corporate needs: a study of software engineers in France. Journal of Engineering and Technology Management 20 (3), 205-230.

Morgan, D.L. (Ed.), 1993. Successful Focus Groups: Advancing the State of the Art. Sage, Newbury Park, CA.

Morris, P.W.G., 1997. The Management of Projects. Thomas Telford, London

Morris, P.W.G., Crawford, L., Hodgson, D., Shepherd, M.M., Thomas, J., 2006. Exploring the role of formal bodies of knowledge in defining a profession: the case of project management. International Journal of Project Management 24 (8), 710-721.

Perrucci, R., 1971. Engineering: professional servant of power. The American Behavioral Scientist 14 (4), 492-506.

Project Management Institute (PMI), 2010. PMI website www.pmi.org, accessed 15 December 2010.

Raelin, J.A., 1986. An analysis of professional deviance within organizations. Human Relations 39 (12), 1103-1129.

Ritti, R., 1968. Work goals of scientists and engineers. Industrial Relations 7 (2), 118-131.

Roberts, K., Biddle, J., 1994. The transition into management by scientists and engineers: a misallocation or efficient use of human resources? Human Resource Management 33 (4), 561-579.

Rynes, S.L., Tolbert, P.S., Strausser, P.G., 1988. Aspirations to manage: a comparison of engineering students and working engineers. Journal of Vocational Behavior 32 (2), 239-253.

Shenhav, Y.A., 1988. Abandoning the research bench: individual, organizational and environmental accounts. Work and Occupations 15 (1), 5-23.

Shenhav, Y.A., 1999. Manufacturing Rationality: The Engineering Foundations of the Managerial Revolution. Oxford University Press, Oxford; New York.

Shepard, H.A., 1956. Nine dilemmas in industrial research. Administrative Science Quarterly 1 (3), 295-309.

Watson, J.M., Meiksins, P.F., 1991. What do engineers want? Work values, job rewards and job satisfaction. Science Technology and Human Values 16 (2), $140-172$.

Whitley, R., 2006. Project-based firms: new organizational form or variations on a theme? Industrial and Corporate Change 15 (1), 77-99.

Yeh, Q.J., 2008. Exploring career stages of midcareer and older engineers: when managerial transition matters. IEEE Transactions on Engineering Management 55 (1), 82-93.

Zussman, R., 1984. The middle levels: engineers and the working middle class. Politics \& Society 13 (3), 217-237. 